\title{
Malignancy Risk Index in Pelvic Mass Differentiation
}

\author{
Nadejda Fainbaum and Claudio Sergio Batista* \\ Department Gynecology \& Obstetrics, Faculty of Medicine of Petropolis, RJ, Brazil
}

Submission: February 07, 2017 ; Published: February 27, 2017

*Corresponding author: Claudio Sergio Batista, Department Gynecology \& Obstetrics, Faculty of Medicine of Petropolis, RJ, Brazil, Tel: 552422313630; 5524992557298; Email: csergiobatista@gmail.com

\begin{abstract}
Ovarian cancer is the seventh major cause of cancer-related death in women. Near $70 \%$ of epithelial ovarian cancers are diagnosed when the disease is advanced, when the 5-year survival rate is, approximately, $25 \%$. The malignancy risk index (MRI) of ovarian tumors associates menopausal status, ultrasound characteristics and CA-125 serum levels, and has the goal of improving the preoperative distinction between benign and malignant ovarian tumors. So, we approuch this tool to regard how we should be find the best way to treat women with pelvic mass. In this paper we made a summarized review of MRI. In this article MRI and its componentes are reviewed. We understand that simplicity of Malignancy Risk Index calculation allows providing, with good accuracy, aid in differential preoperative diagnosis between benign and malignant tumors.
\end{abstract}

Keywords: Ovarian neoplasms; Risk Index; Diagnosis; Biomarkers tumor; Ultrasonography; CA-125 antigen

\section{Introduction}

\section{Epidemiology of ovarian cancer}

Ovarian cancer is the seventh most common cancer among women, with 238,719 cases/year (3.6\%). In 2012 it was estimated the mortality of 151,917 cases per year. It is the third most common gynecological cancer, after cancer of the cervix and uterine body. Its incidence is variable in different regions of the world, being greater in northern countries and Eastern Europe and less in Southeast Asia and Africa [1].

Ovarian cancer is the most lethal Gynecological tumors, being the most difficult to be diagnosed and with lower chances of cure. More women die of ovarian cancer than any other gynecological. About of. 75 of this organ cancers are at an advanced stage at diagnosis [2].

\section{Pathology of ovarian cancer}

Epithelial tumors account for about $90 \%$ of cases of ovarian cancer, corresponding to the vast majority of primary neoplasms, other types are the germ line or stromal tumors. Although referred to as epithelial, they derive from the mesothelium surface coelomic. There are three main types of these tumors: serous, mucinous and endometrioid, being the frequent occurrence of tumors with mixed component. Other histological subtypes which also emerge from the epithelial lining are the clear cell tumors and tumor of Brenner, both with low frequency, representing $1 \%$ to $3 \%$ of all ovarian tumors. Serosos of tumors benign, borderline and malignant types account for about 30\% of all ovarian tumors. Cistoadenocarcinomas serosos account for approximately $40 \%$ of all ovarian tumors, being the most common malignancies in this organ. Mucinosos tumors are less common, accounting for approximately $25 \%$ of all ovarian neoplasms. Cistoadenocarcinomas mucinosos account for only $10 \%$ of all ovarian cancers. Endometrióides tumors are responsible for about $20 \%$ of ovarian tumors [3].

The most common form of dissemination of epithelial tumours is through exfoliation of malignant cells from the surface of ovarian capsule to the peritoneal cavity, causing peritoneal implants. The spread to the lymph nodes is common, and approximately $10 \%$ of patients with ovarian cancer to lymph nodes metastases to feature located-aortic [3].

\section{Diagnosis of ovarian cancer}

For ovarian tumor diagnosis is necessary to evaluate the clinical history, physical exam, transvaginal ultrasound finds, and especially in postmenopausal, the determination of serum CA125 level. 


\section{Tumor markers}

Tumor markers are substances can be detected and quantified in blood or other organic fluids of patients with neoplasms. The ideal marker must be produced for all tumors of the same lineage and their levels should be measurable even in presence of small amount of cells. Serum levels should accurately reflect the clinical evolution and regression of the disease, being their normalization associated to disease cure. Must be sensitive and specific, present proportional levels to the tumor size, useful in establishing prognosis, anticipate the occurrence of recurrences and allow the selection of treatment. None of the markers studied so far has all these features [4].

As any additional test for diagnosis, tumor markers have precise indications and are debatable. Serum value provided by the laboratory needs to be valued with epidemiological and critical sense, with the characteristics of each marker and the technique used for detecting

\section{Risk of malignancy index (MRI)}

With the aim of improving prediction of malignancy of ovarian tumors efficiency, Jacobs et al. [5]. in 1990, proposed the Malignancy Risk Index (MRI) associating ultrasound parameters, tumor marker CA-125 and the menopausal status. For MRI calculation CA-125 value is multiplied by the value obtained through the ultrasound parameters and the value associated with menopausal status IRM = Ux M x C 125. Cut-off value of 200 showed sensitivity of $85.4 \%$, specificity of $96.9 \%$, positive predictive value of $42.1 \%$ and negative predictive value of $0.15 \%$. In 2006, Bailey et al. [6]. remade the same study and confirmed the effectiveness of the risk of malignancy Index in potential cases of ovarian malignant neoplasm in assessing the accuracy of this content. Between malignant cases included in your study, $87.4 \%$ presented positivity in criterion established.

In general It has been demonstrated that using a cut-off point of 200 (irrespective of the score system) to evaluate a risk of malignancy index achieved a sensitivity of between $70 \%$ and $87 \%$, and specificity of $89 \%$ and $97 \%$. However, the risk of malignancy index uses ultrasound, which is operator-dependent, and this is subject to the equipment's image resolution capacity and possible variation between patient populations $[7,8]$.

\section{Ultrasound}

Ultrasound study must be correlated with the history and laboratory tests. Morphological evaluation of anexiais masses with ultrasonography can help in the constraint of differential diagnoses, however, cannot always distinguish between benign and malignant masses [9]. When used as the only method of screening, presents a sensitivity of $75 \%$ and specificity of $73 \%$ on presumption of malignant tumors [10]. Cystic and solid masses differentiation with better characterization of septa, mural nodules and echogenicity of cystic and complex masses are important roles of the ultrasound examination [11]
Ultrasound with color dopplerfluxometria was proposed by Salem et al. to help distinguish benign and malignant adnexal masses. Malignant masses are usually vascular and the morphology of low doppler resistance seen in malignant lesions can also be demonstrated in inflammatory masses, vascular benign neoplasms, endometriomas, corpus luteum cysts and ectopic pregnancy [12].

\section{CA-125}

The most well-known tumor marker and used in monitoring of patients with epithelial ovarian tumors is the CA-125 (Cancer Antigen 125), a sialomucina of high molecular weight. This was initially identified by means of antibodies produced by animals immunized with cistoadenocarcinoma cells of serous ovarian câncer [13].

CA-125 can be found at low levels in healthy people, in both sexes. There are physiological conditions in which there is CA 125 values elevation such as menstruation, endometriosis patients and pregnant women in the first trimester [14]. In isolation, is the best scorer of the malignant tumors of the ovary, but does not present considerable sensitivity and specificity for risk assessment [15]. In epithelial type sensitivity for diagnosis of ovarian cancer is $80 \%$ to $85 \%$. Varying according to the staging, being $50 \%$ in stage I, $90 \% 92 \%$ at the stage II, stage III and the $94 \%$ in stage IV [16].

CA-125 elevation occurs in about $85 \%$ of women in advanced stages of ovarian neoplasms, however, in early stages, increases by only $50 \%$ of patients. Often it is also elevated in benign tumors of ovary [17]. The elevation of CA-125 can occur from two to twelve months before any clinical evidence of recurrence.

\section{General Considerations}

The possibility of a diagnostic of ovarian malignancy must be considered in the presence of an adnexal mass. A detailed preoperative assessment, considering the medical history and the results of the complementary examinations, are essential for the proper conduct of these cases and Malignancy Risk Index is a simple algorithm to apply in pelvic masses, and we consider as its main advantage for distinction between benign and malignant ovarian tumors when compared to other more complex parameters such as dopplervelocimetria, or more expensive as the use of multiple tumor markers, is that MRI features of high accuracy rates and with less cost.

\section{References}

1. Ferlay J, Soerjomataram I, Ervik M, Dikshit R, Eser S, Mathers C, et al. (2012) Cancer Incidence and Mortality Worldwide: IARC Cancer Base No. 11 [Internet]. Globocan 1.

2. Ries LAG, Young JL, Keel GE, Eisner MP, Lin YD, et al. (2007) SEER Survival Monograph: Cancer Survival Among Adults: U.S. SEER Program, 1988-2001, Patient and Tumor Characteristics. National Cancer Institute, SEER Program, Bethesda, USA.

3. Baracat EC, Soares JM (2016) Condutas em Ginecologia Baseadas em Evidências - Protocolos Assistenciais - Clínica Ginecológica - Hospital das Clínicas - FMUSP. São Paulo, Editora Atheneu, Brazil. 
4. Reis FJC (2005) Rastreamento e diagnóstico das neoplasias de ováriopapel dos marcadores tumorais. Rev Bras Ginecol Obstet 27(4): 222227.

5. Jacobs I, Oram J, Fairbanks J, Turner J, Frost C, et al. (1990) A risk of malignancy index incorporating CA 125 , ultrasound and menopausal status for the accurate preoperative diagnosis of ovarian cancer. $\mathrm{Br} \mathrm{J}$ Obstet Gynecol 97(10): 922-929.

6. Bailey J, Tailor A, Naik R, Lopes A, Godfrey K, et al. (2006) Risk of malignancy index for referral of ovarian cancer cases to a tertiary center: does it identify the correct cases? Int J Gynecol Cancer 16(Suppl 1): $30-34$

7. Ong C, Biswas A, Choolani M, Low JJ (2013) Comparision of risk of malignancy indices in evaluating ovarian masses in Southeast Asian population. Singapore Med J 54(3): 136-139.

8. Cruz Morales RA, Pavón Hernández CM, Pacheco Bravo I (2014) Utilidad de la evaluación ecográfica en la caracterización delas lesiones ováricas y su correlación histopatológica. Gaceta Mexicana de Oncología 13: 370-712.

9. Fleischer AC (1991) Transabdominal and transvaginal sonography of ovarian masses. Clin Obstet Gyn 34(2): 433-442.

10. Torres J, Mauricette S, Faúndes A, Gontijo R, Martinez E, et al. (2002) Risk-of-Malignancy Index in preoperative evaluation of clinically restricted ovarian cancer. Rev Paul Med. 120(3): 72-76.
11. Mendelson EB, Bohm-Velez M, Joseph N, Neiman HL (1988) Gynecologic imaging: comparison of transabdominal and transvaginal sonography. Radiology 166(2): 321-324.

12. Fleischer AC, Rodgers WH, Rao BK, Keppler DM, Worrell JA, et al. (1991) Assessment of ovarian tumor vascularity with transvaginal color Doppler sonography. J Ultrasound Med 10(10): 563-568.

13. Bast RC, Feeney M, Lazarus H, Nadler LM, Colvin RB, et al. (1981) Reachvity of a monoclonal antibody with human ovarian carcinoma. J Clin Invest. 1981; 68(5): 1331-1337.

14. Haga Y, Sakamoto K, Egami H, Yoshimura R, Akagi M (1986) Evaluation of serum CA 125 values in healthy individuals and pregnant women. Am J Med Sci 292(1): 25-29.

15. McIntosh MW, Drescher C, Karlan B, Scholler N, Urban N, et al. (2004) Combining CA 125 and SMR serum markers for diagnosis and early detection of ovarian carcinoma. Gynecol Oncol 95(1): 9-15.

16. Jacobs I, Bast JR RC (1989) The CA 125 tumour-associated antigen: a review of the literature. Hum Reprod 4(1): 1-12.

17. Cannistra SA (1993) Cancer of the ovary. N Engl J Med 329(21): 15501559.

\section{Your next submission with Juniper Publishers} will reach you the below assets

- Quality Editorial service

- Swift Peer Review

- Reprints availability

- E-prints Service

- Manuscript Podcast for convenient understanding

- Global attainment for your research

- Manuscript accessibility in different formats

( Pdf, E-pub, Full Text, Audio)

- Unceasing customer service

Track the below URL for one-step submission https://juniperpublishers.com/online-submission.php 